\title{
EFEKTIVITAS INSTAGRAM DALAM MENINGKATKAN PENGETAHUAN SADARI SEBAGAI PENCEGAHAN DINI KANKER PAYUDARA
}

\author{
Ervi Rachma Dewi ${ }^{1}$, Lutfi Nihayani ${ }^{2}$ \\ Program Studi Kesehatan Masyarakat ${ }^{1,2}$ \\ Sekolah Tinggi Ilmu Kesehatan Cendekia Utama Kudus ${ }^{1,2}$ \\ rachmadewiakbar@gmail.com¹, lutfinihayani03@gmail.com²
}

\begin{abstract}
Breast cancer is one of the cancers that cause women's death, because women who fail to realize why they have cancer. The high risk of breast cancer is caused by breast cancer education since adolescents in protection and early breast cancer. Based on the initial survey, it was found that $92.5 \%$ of 40 teenagers in Kudus did not know BSE, and $7.5 \%$ of 40 teenagers had heard the term BSE. Instagram as one of the information media that is widely used today can be used as a health promotion media. This research reveals knowledge of Instagram social media in increasing BSE knowledge as an early increase in cancer in adolescents in the Kudus district. The type and design of this study was preexperimental with the One Group Pretest-Posttest Design. The sample in this study was adolescents in various high schools in Kudus Regency with 90 adolescents. The research instrument was questionnaire and Instagram media with AISAS. The data analysis of this research is univariate analysis to determine the level of knowledge and media instagram with AISAS while the bivariate analysis using Wilcoxon test. Based on the results of the study the average value before intervention 47.78 and intervention 74.50 , the level of awareness of adolescents about BSE both 46 (51.1\%) and sufficient 44 (48.9\%) with the Wilcoxon test results obtained a value of $0,0001(p<0.05)$. Average score of average knowledge before and after health promotion using Instagram social media with a score of 55.92\%, Instagram social media effectively provides educational information.
\end{abstract}

Key Words $\quad$ : Health Promotion, BSE, Knowledge, Instagram

\begin{abstract}
ABSTRAK
Kanker payudara merupakan salah satu kanker penyebab kematian wanita, karena wanita biasanya terlambat menyadari bahwa sebenarnya mereka sudah terserang kanker. Tingginya kasus kanker payudara dikarenakan kurangnya edukasi kanker payudara sejak remaja dalam mendeteksi dan menangani kanker payudara secara dini. Berdasarkan survei awal, diperoleh 92,5\% dari 40 remaja di Kabupaten Kudus tidak mengetahui SADARI, dan 7,5\% dari 40 remaja pernah mendengar istilah SADARI. Instagram sebagai salah satu media informasi yang banyak digunakan saat ini dapat dimanfaatkan sebagai media promosi kesehatan. Penelitian ini bertujuan mengetahui efektivitas media sosial instagram dalam meningkatkan pengetahuan SADARI sebagai pencegahan dini kanker pay udara pada remaja di Kabupaten Kudus. Jenis dan rancangan penelitian ini merupakan pra eksperimen dengan rancangan One Group Pretest-Posttest Design. Sampel pada penelitian ini adalah remaja di berbagai SMA di Kabupaten Kudus dengan jumlah 90 remaja. Instrumen penelitian dengan kuesioner dan media instagram dengan AISAS. Analisis data penelitian ini yaitu analisis univariat untuk mengetahui tingkat pengetahuan dan media instagram dengan AISAS sedangkan analisis bivariat dengan menggunakan uji wilcoxon. Berdasarkan hasil penelitian menunjukkan nilai rata-rata sebelum intervensi 47,78 dan sesudah intervensi 74,50, tingkat pengetahauan remaja tentang SADARI baik $46(51,1 \%)$ dan cukup 44 $(48,9 \%)$ dengan hasil uji wilcoxon didapatkan nilai $0,0001(\mathrm{p}<0,05)$. Terdapat perbedaan skor ratarata pengetahuan sebelum dan sesudah promosi kesehatan menggunakan media sosial instagram dengan kenaikan skor 55,92\%, media sosial instagram efektif dalam memberikan informasi pendidikan.
\end{abstract}

Kata Kunci : Instagram, Pengetahuan, Promosi Kesehatan, SADARI 


\section{PENDAHULUAN}

Kanker payudara merupakan salah satu kanker penyebab kematian wanita, karena wanita biasanya terlambat menyadari bahwa sebenarnya mereka sudah terserang kanker. Keadaan tersebut, biasanya baru disadari setelah kanker masuk pada stadium lanjut. Sehingga tidak ada proses deteksi dini yang dapat memperlambat atau bahkan menyembuhkan kanker tersebut sejak dini (Savitri et al., 2015). Data Global Cancer Observatory 2018 dari World Health Organization (WHO) menunjukkan kasus kanker yang paling banyak terjadi di Indonesia adalah kanker payudara, yakni 58.256 kasus atau $16,7 \%$ dari total 348.809 kasus kanker. Kementerian Kesehatan (Kemenkes) menyatakan, angka kanker payudara di Indonesia mencapai 42,1 orang per 100 ribu penduduk. Rata-rata kematian akibat kanker ini mencapai 17 orang per 100 ribu penduduk (WHO, 2019, dalam databoks).

Pada tahun 2017 kasus kanker payudara di Kabupaten Kudus menempati urutan ke18 dari 36 Kabupaten di Jawa Tengah, sedangkan pada tahun 2018 kasus kanker payudara di Kabupaten Kudus meningkat pada urutan ke-7 dari 36 Kabupaten di Jawa Tengah (Profil Kesehatan Jawa Tengah 2018). Di Kabupaten Kudus tahun 2018 dari berbagai kecamatan terdapat jumlah kasus kanker payudara sebanyak 69, sedangkan di berbagai RS yang berada di Kabupaten Kudus sebanyak 223 kasus kanker payudara (Dinas Kesehatan Kabupaten Kudus, 2018). Pada tahun 2019 data yang ada di Dinas Kesehatan Kabupaten Kudus diberbagai kecamatan meningkat menjadi 109 kasus kanker payudara, sedangkan di berbagai RS data yang ada turun menjadi 58 kasus kanker payudara (Dinas Kesehatan Kabupaten Kudus, 2019).

Tingginya kasus kanker payudara dikarenakan kurangnya edukasi kanker payudara sejak remaja dalam mendeteksi dan menangani kanker payudara secara dini (Pamungkas, 2015). Berdasarkan data survei awal yang dilakukan peneliti pada 40 remaja di Kabupaten Kudus, didapatkan data $92,5 \%$ dari 40 remaja tersebut tidak mengetahui SADARI, dan 7,5\% dari 40 remaja pernah mendengar istilah SADARI dari media maupun tenaga kesehatan.

Pengguna media sosial di Indonesia mencapai 150 juta atau sebesar $56 \%$ dari total populasi. Jumlah tersebut naik $20 \%$ dari survei sebelumnya. Sementara pengguna media sosial mobile (gadget) mencapai 130 juta atau sekitar $48 \%$ dari populasi (databoks, 2019). Survei awal penggunaan media sosial pada 40 remaja di Kabupaten Kudus 100\% menggunakan media sosial baik berupa facebook maupun instagram, penggunaan facebook pada 40 remaja $7,5 \%$ sedangkan penggunaan instagram dari 40 remaja tersebut $92,5 \%$ dikarenakan instagram menjadi trend untuk saat ini dibandingkan facebook. Remaja di Kabupaten Kudus menggunakan media sosial 25\% dikarenakan untuk mengisi waktu istirahat, dan $75 \%$ untuk mencari informasi.

Promosi kesehatan tidak terlepas dari kegiatan atau usaha menyampaikan pesan kesehatan kepada masyarakat, kelompok, atau individu. Dengan adanya pesan yang telah diberikan diharapkan masyarakat, kelompok atau individu dapat memperoleh pengetahuan tentang kesehatan yang lebih baik. Dengan adanya promosi kesehatan tentang SADARI sehingga dapat merubah perilaku masyarakat, kelompok atau individu (Notoatmodjo, 2014). Metode promosi kesehatan menggunakan jejaring sosial dirasakan relatif lebih murah dan lebih mudah untuk diakses, untuk menyampaikan serta mendapat informasi.

Endah Risnawati (2015) dalam penelitiannya di Pondok Pesantren Rohmatillah Desa Besito Kecamatan Gebog Kabupaten Kudus mengungkapkan bahwa tingkat pengetahuan pemeriksaan payudara sendiri (SADARI) pada remaja kurang, hal ini dikarenakan minimnya informasi tentang pemeriksaan payudara sendiri (SADARI) dengan didapatkan hasil nilai chi square hitung $>$ nilai chi square tabel, dan nilai probabilitas di bawah 0,05 yang dapat 
disimpulkan bahwa terdapat hubungan yang signifikan antara tingkat pengetahuan SADARI dan praktik SADARI pada remaja putri. Penelitian promosi kesehatan menggunakan media sosial instagram maupun facebook sudah pernah dilakukan oleh Rita Permatasari terkait promosi kesehatan tentang Dagusibu (Cara Tepat Penggunaan Obat) melalui media sosial instagram maupun facebook pada mahasiswa Universitas Muhammadiyah Purwokerto dengan hasil bahwa media sosial Instagram maupun facebook mempunyai efektivitas yang sama dalam meningkatkan pengetahuan tentang Dagusibu di Universitas Muhammadiyah Purwokerto. Berdasarkan latar belakang di atas maka dilakukan penelitian dengan judul "Efektivitas Media Sosial Instagram dalam Meningkatkan Pengetahuan SADARI sebagai Pencegahan Dini Kanker Payudara pada remaja di Kabupaten Kudus", dengan tujuan untuk mengetahui efektivitas media sosial instagram dalam meningkatkan pengetahuan SADARI sebagai pencegahan dini kanker payudara pada remaja di Kabupaten Kudus.

\section{METODE}

Jenis penelitian yang digunakan yaitu penelitian pra eksperimen (Pre eksperimental), dengan rancangan "One Group Pretest-Posttest Design". Di dalam penelitian ini tidak ada kelompok pembanding (kontrol) tetapi paling tidak sudah dilakukan pretest yang memungkinkan peneliti dapat menguji perubahan-perubahan yang terjadi setelah adanya eksperimen.

Penelitian ini dilakukan di beberapa organisasi pendidikan wilayah Kabupaten Kudus. Penelitian ini telah dilaksanakan pada tanggal 01 - 06 April 2020. Populasi dalam penelitian ini adalah remaja perempuan SMA/MA/SMK yang berusia antara 15 tahun - 18 tahun, yang bertempat tinggal di wilayah Kabupaten Kudus dengan jumlah 90 responden. Sampel yang digunakan dalam penelitian ini menggunakan teknik cluster sampling yang dilakukan dengan dua tahap yaitu, tahap penentuan daerah dan tahap penentuan individu (Sugiyono, 2017).

Pada tahap penentuan daerah dilakukan di berbagai instansi sekolah sekitar kampus STIKES Cendekia Utama Kudus, yaitu di SMA 1 Mejobo, SMA 1 Bae, MAN 1 Kudus dan SMA 2 Bae, SMK 2 Kudus, sedangkan pada tahap kedua, dilakukan tahap penentuan sampel individu. Pengambilan sampel dilakukan random atau acak, dari masing- masing sekolah yang sudah terpilih.

Instrumen dalam penelitian ini adalah kuesioner pretest, posttest, dan media instagram dengan AISAS. Analisis data penelitian ini yaitu analisis univariat untuk mengetahui tingkat pengetahuan dan media instagram dengan AISAS sedangkan analisis bivariat dengan menggunakan uji wilcoxon.

\section{HASIL}

\section{Analisis Univariat \\ Karakteristik Responden Menurut Umur}

\section{Tabel 1 Distribusi Responden Menurut}

\begin{tabular}{ccc}
\multicolumn{2}{c}{ Umur } & \\
\hline $\begin{array}{c}\text { Umur } \\
\text { (Tahun) }\end{array}$ & Jumlah & $(\%)$ \\
\hline 15 & 12 & 13,3 \\
16 & 39 & 43,3 \\
17 & 31 & 34,4 \\
18 & 8 & 8,9 \\
\hline Total & 90 & 100
\end{tabular}

Sumber : Data Primer, 2020

Tabel 1 menunjukkan bahwa dari 90 responden yang berusia 15 tahun sebanyak $12(13,3 \%)$ responden, usia 16 tahun sebanyak $39(43,3 \%)$ responden, usia 17 tahun sebanyak $31(34,4 \%)$ responden dan usia 18 tahun sebanyak $8(8,9 \%)$ responden. Kelompok eksperimen paling banyak yaitu usia 16 tahun dan paling sedikit usia 18 tahun. 
Pertanyaan AISAS (Attention, Interest, Search, Action, Share)

Model AISAS merupakan singkatan dari Attention, Interest, Search, Action, dan Share (Dewanti 2019). Berikut adalah penjabaran dari model AISAS menurut Sugiyama dalam Rahmawati (2019). Berikut pertanyaan tentang AISAS Instagram (Sugiyama dalam Rahmawati (2019) dengan modifikasi):

\section{a. Attention}

1)Saya mengetahui Sadari pertama dari instagram

@informasikesehatanmasyarakat

2)Postingan di feed instagram @informasikesehatanmasyarakat sudah menarik

b. Interest

1)Melihat informasi kesehatan yang di posting, saya menjadi tertarik untuk memahami isi informasi

2) Saya merasa takut setelah tahu bahwa Kanker Payudara penyebab kematian

c. Search

1)Saya melakukan pencarian lebih lanjut melalui internet tentang informasi SADARI sebagai pencegahan dini kanker payudara

2)Pada informasi akun @informasikesehatanmasyarakat menekankan bahwa saya harus dapat melakukan pencegahan dini kanker payudara

d. Action

1)Saya tertarik untuk melakukan SADARI seperti yang dijelaskan dalam akun@informasikesehatanmasyarakat

2) Saya yakin bahwa informasi yang diberikan sangat bermanfaat

e. Share

1) Saya akan menyampaikan informasi ini ke teman- teman atau saudara melalui chat

2) Saya akan membuat instastory agar kerabat saya tahu tentang informasi kesehatan khususnya SADARI
Tabel 2 Distribusi analisis responden tentang AISAS Instagram

$\begin{array}{llll}\text { No } & \text { Setuju } & \begin{array}{c}\text { Kurang } \\ \text { setuju }\end{array} & \begin{array}{c}\text { Tidak } \\ \text { setuju }\end{array}\end{array}$

\begin{tabular}{ccccccc} 
& $\mathbf{n}$ & $\mathbf{\%}$ & $\mathbf{n}$ & $\mathbf{\%}$ & $\mathbf{n}$ & $\mathbf{\%}$ \\
\hline 1 & 72 & 80 & 13 & 14,4 & 5 & 5,6 \\
\hline 2 & 81 & 90 & 9 & 10 & 0 & 0 \\
\hline 3 & 86 & 95,6 & 4 & 4,4 & 0 & 0 \\
\hline 4 & 72 & 80 & 15 & 16,7 & 3 & 3,3 \\
\hline 5 & 70 & 77,8 & 18 & 20 & 2 & 2,2 \\
\hline 6 & 87 & 96,7 & 3 & 3,3 & 0 & 0 \\
\hline 7 & 86 & 95,6 & 4 & 4,4 & 0 & 0 \\
\hline 8 & 90 & 100 & 0 & 0 & 0 & 0
\end{tabular}

Sumber : Data Primer, 2020

Tabel 2 menunjukkan bahwa dari 10 pertanyaan tentang AISAS Instagram yang setuju lebih banyak dibandingkan dengan yang tidak setuju. AISAS dalam penelitian ini yaitu berbagai tahap untuk mengetahui pengaruh dalam promosi kesehatan menggunakan instagram khususnya tentang SADARI dimana dijelaskan bahwa pertanyaan AISAS dengan keterangan nomor 1 dan 2 merupakan pertanyaan attention, nomor 3 dan 4 merupakan pertanyaan interest, nomor 5 dan 6 pertanyaan search, nomor 7 dan 8 pertanyaan action dan nomor 9 dan 10 pertanyaan share. Berdasarkan tabel diatas diketahui bahwa jawaban responden yang banyak setuju yaitu pada pertanyaan action pada soal nomor 8 dengan jumlah jawaban responden setuju 90 (100\%) dan paling sedikit pada pertanyaan share pada soal nomor 10 dengan jumlah jawaban responden setuju $67(74,4 \%)$, dan untuk jawaban yang banyak kurang setuju yaitu pertanyaan share pada soal nomor 10 dengan jumlah jawaban responden kurang setuju $22(24,4 \%)$ dan paling sedikit yaitu pertanyaan action pada soal nomor 8 yaitu dengan jawaban responden kurang setuju 0 $(0 \%)$, sedangkan jawaban tidak setuju paling banyak yaitu pertanyaan attention pada soal nomor 1 yaitu dengan jawaban responden tidak setuju $5(5,6 \%)$, dan untuk yang paling sedikit tidak setuju yaitu soal 
nomor 2,3,6,7,8,9 dengan jawaban responden tidak setuju $0(0 \%)$.

Pengetahuan Remaja Tentang SADARI Sebagai Pencegahan Dini Kanker Payudara Sebelum Diberikan Media Sosial Instagram

Tabel 3 Distribusi tingkat pengetahuan remaja tentang SADARI

Tingkat pengetahuan

Pretest

\begin{tabular}{lcc}
\cline { 2 - 3 } \multicolumn{1}{r}{ pengetahuan } & n & \% \\
\hline Baik & 0 & 0 \\
\hline Cukup & 14 & 15,6 \\
\hline Kurang & 76 & 84,4
\end{tabular}

Sumber : Data Primer, 2020

Berdasarkan tabel 3 distribusi pengetahuan remaja tentang SADARI sebagai pencegahan dini kanker payudara sebelum diberikan media sosial instagram, menunjukkan bahwa dari 90 responden didapatkan tingkat pengetahuan kategori baik sebanyak $0(0 \%)$ responden, kategori cukup sebanyak $14(15,6 \%)$ responden, sedangkan tingkat pengetahuan kategori kurang sebanyak $76(84,4 \%)$ responden, dan dari tabel diatas menunjukkan bahwa dari 90 responden diperoleh skor rata-rata adalah 47,78 dengan median 50,00, sedangkan skor minimum adalah 25 dan skor maksimum 65 , serta standar deviasi sebesar 8,77.

Tingkat Pengetahuan Remaja Tentang SADARI Sebagai Pencegahan Dini Kanker Payudara Sesudah Diberikan Media Sosial Instagram

Tabel 4 Distribusi tingkat pengetahuan remaja tentang SADARI

\begin{tabular}{lcc}
\hline \multirow{2}{*}{$\begin{array}{c}\text { Tingkat } \\
\text { pengetahuan }\end{array}$} & \multicolumn{2}{c}{ Postest } \\
\cline { 2 - 3 } & n & \% \\
\hline Baik & 46 & 51,1 \\
\hline Cukup & 44 & 48,9 \\
\hline Kurang & 0 & 0 \\
\hline
\end{tabular}

Sumber : Data Primer, 2020

Berdasarkan tabel 4 distribusi pengetahuan remaja tentang SADARI sebagai pencegahan dini kanker payudara sesudah diberikan media sosial instagram, menunjukkan bahwa dari 90 responden didapatkan tingkat pengetahuan kategori baik sebanyak $46(51,1 \%)$ responden, kategori cukup sebanyak $44 \quad(48,9 \%)$ responden, sedangkan tingkat pengetahuan kategori kurang sebanyak $0(0 \%)$ responden, dan dari tabel diatas menunjukkan bahwa dari 90 responden diperoleh skor rata-rata adalah 74,50 dengan median 75,00, sedangkan skor minimum adalah 50 dan skor maksimum 100, serta standar deviasi sebesar 14,32 .

\section{Analisis Bivariat \\ Uji Normalitas Data}

Pengujian normalitas data diperlukan untuk mengetahui data tersebar secara normal atau tidak sebelum dilakukan analisis uji hipotesis. Uji normalitas data yang digunakan pada penelitian ini adalah uji kolmogorov smirnov karena sampel lebih dari 50. Apabila data terdistribusi normal maka uji selanjutnya yang dilakukan adalah uji t-test berpasangan, namun apabila data tidak terdistribusi normal dilakukan uji alternatif yaitu uji wilcoxon. Adapun variabel yang di uji meliputi variabel pretest dan posttest. Berikut ini adalah hasil tabel uji normalitas data:

\section{Tabel 5 Hasil Uji Normalitas Data}

\begin{tabular}{ccc}
\hline Hasil & Pretest & Posttest \\
\hline P value & 0,0001 & 0,022 \\
\hline
\end{tabular}

Sumber : Data Primer, 2020

Berdasarkan tabel 5 tentang hasil uji normalitas data, diketahui bahwa nilai $\mathrm{p}$ value pada pretest yaitu 0,001 dan posttest adalah 0,022 . Karena nilai probabilitas ( $p$ value) pada pretest dan posttest keduanya kurang dari 0,05 maka dapat disimpulkan bahwa semua data tidak terdistribusi normal yang artinya pada penelitian ini tidak bisa menggunakan uji t-test berpasangan melainkan menggunakan uji alternatifnya berupa uji wilcoxon. 
Efektivitas Media Sosial Instagram dalam Meningkatkan Pengetahuan SADARI sebagai Pencegahan Dini Kanker Payudara pada Remaja

Media sosial instagram dikatakan efektif dalam meningkatkan pengetahuan SADARI sebagai pencegahan dini kanker payudara pada remaja di Kabupaten Kudus jika skor posttest lebih besar daripada skor pretest. Berikut ini adalah uji wilcoxon dan prosentase kenaikan skor antara pretest dan posttest.

Tabel 6 Efektivitas Media Sosial dalam Meningkatkan Pengetahuan SADARI

\begin{tabular}{ccccc}
\hline Hasil & $\mathbf{N}$ & Mean & $\begin{array}{c}\text { Kenaikan } \\
\text { skor (\%) }\end{array}$ & P value \\
\cline { 1 - 3 } Pretest & 90 & 47,78 & 55,92 & 0,0001 \\
\cline { 1 - 1 } Post test & & 74,50 & & \\
\hline
\end{tabular}

Sumber : Data Primer, 2020

Berdasarkan tabel 6 dari 90 responden menunjukkan hasil sebelum intervensi menggunakan media sosial instagram didapatkan skor rata-rata 47,78 dan sesudah intervensi mendapatkan skor rata-rata 74,50. Hasil uji wilcoxon didapatkan nilai $p$ value $0,0001<0,05$ pada taraf signifikan 5\% bahwa terdapat perbedaan yang signifikan antara pretest dan postttest dengan prosentase kenaikan skor antara pretest dan posttest sebesar $55,92 \%$ yang berarti media sosial instagram efektif terhadap peningkatan pengetahuan tentang SADARI sebagai pencegahan dini kanker payudara pada remaja di Kabupaten Kudus.

\section{PEMBAHASAN}

\section{Pengetahuan Remaja Tentang SADARI Sebelum Diberikan Intervensi}

Responden mengisi kuesioner pretest terlebih dahulu dengan daring/online menggunakan google form yang telah disediakan peneliti sebelum dilakukan intervensi menggunakan media sosial instagram dengan akun yang telah dipersiapkan sebelumnya. Berdasarkan hasil penelitian menunjukkan pengetahuan remaja tentang SADARI sebagai pencegahan dini kanker payudara sebelum diberikan intervensi dengan media sosial instagram sebanyak 90 responden didapatkan tingkat pengetahuan baik $0(0 \%)$ responden, tingkat pengetahuan cukup sebanyak $14 \quad(15,6 \%)$ responden, pengetahuan kurang sebanyak $76(84,4 \%)$ responden, dan didapatkan nilai rata-rata pengetahuan sebelum intervensi media sosial instagram sejumlah 47,78 dengan nilai minimal 25 dan maksimal 65, hal ini disebabkan karena remaja di Kabupaten Kudus belum mendapatkan sosialisasi atau pendidikan kesehatan reproduksi khususnya kesehatan payudara.

Hasil penelitian sebelumnya diberikan intervensi media sosial instagram tingkat pengetahuan remaja sebagian besar kurang $(84,4 \%)$ dapat disebabkan oleh faktor usia. Hal ini dapat dijelaskan bahwa saat semakin bertambah usia (cukup umur) maka pengalaman, pengetahuan, dan tingkat kematangan serta kekuatan seseorang akan semakin bertambah, artinya seseorang yang cukup umur maka daya berpikir dan bekerja akan semakin tinggi. (Surajiyo dikutip dalam Sri, Sari 2012). Penelitian ini juga sejalan dengan hasil penelitian yang dilakukan oleh (Suastina, I. D.A. R, et al 2013), bahwa tingkat pengetahuan pendidikan kesehatan tentang SADARI sebelum diberikan intervensi sebagian besar kurang. Ada banyak faktor yang mempengaruhi pengetahuan seseorang, baik faktor internal maupun faktor eksternal. Faktor internal yang mempengaruhi pengetahuan seseorang yaitu umur, pengalaman, pendidikan, jenis kelamin, pekerjaan dan lain-lain. Sedangkan faktor eksternalnya adalah lingkungan, paparan informasi, dan sosial budaya.

\section{Pengetahuan Remaja Tentang SADARI Sesudah Diberikan Intervensi}

Responden mengisi kuesioner posttest setelah diberi intervensi media sosial instagram dengan daring/online menggunakan google form yang telah disediakan peneliti. Sebelum mengisi posttest responden mengisi kuesioner yang berisi tentang feed back (AISAS) dari 
instagram pengetahuan SADARI sebagai pencegahan dini Kanker Payudara.

Berdasarkan hasil penelitian feed back (AISAS) instagram tentang SADARI sebagai pencegahan dini kanker payudara menunjukkan bahwa responden menyatakan setuju pada pertanyaan AISAS yaitu pada poin action, sedangkan yang banyak kurang setuju pada poin share dan yang paling banyak tidak setuju diantara pertanyaan AISAS yaitu pada attention. Feed back (AISAS) paling banyak yaitu pada action yang dapat diartikan bahwa pesan/informasi yang diperoleh dari media sosial instagram @informasikesehatanmasyarakat telah berhasil mendorong khalayak untuk melakukan tindakan (Rahmawati, 2019), dan pada akhirnya responden diharapkan menerima informasi kesehatan dengan baik serta dapat melakukan dengan benar tentang SADARI sehingga memperoleh kesehatan yang lebih khususnya kesehatan pada payudara.

Berdasarkan hasil penelitian sesudah diberikan intervensi media sosial instagram menunjukkan pengetahuan remaja tentang SADARI sebagai pencegahan dini kanker payudara sebanyak 90 responden didapatkan tingkat pengetahuan baik 46 $(51,1 \%)$ responden, tingkat pengetahuan cukup sebanyak $44(48,9 \%)$ responden, pengetahuan kurang sebanyak $0 \quad(0 \%)$ responden, dan didapatkan nilai rata-rata pengetahuan sesudah intervensi media sosial instagram sejumlah 74,50 dengan nilai minimal 50 dan maksimal 100 .

Penyampaian informasi melalui media sosial instagram lebih banyak ditunjukkan oleh foto atau video. Gambar atau foto memiliki banyak kelebihan dibandingkan dengan kata-kata, antara lain sifatnya lebih konkret artinya menunjukkan pokok masalah yang lebih realistis, gambar dapat mengatasi keterbatasan ruang dan waktu, dan dapat memperjelas suatu masalah (Sulaeman Amir, 2015). Pengetahuan dapat diterima melalui panca indera. Menurut penelitian para ahli indera, yang paling banyak menyalurkan pengetahuan ke dalam otak adalah "mata". Kurang lebih 75\% sampai $87 \%$ dari pengetahuan manusia diperoleh atau disalurkan melalui mata (Suryani, Eko. 2013).

Proses sosialisasi kesehatan reproduksi tentang payudara dengan penggunaan media sosial instagram merupakan sosialisasi dengan peraga visual dalam pendidikan promosi kesehatan, hal ini adalah salah satu alternatif untuk mempermudah cara penyampaian dan penerimaan informasi atau bahan pendidikan bagi remaja, sehingga dapat mengoptimalkan kemampuan, penalaran dan keterampilan dalam meningkatkan pengetahuan remaja tentang SADARI sebagai pencegahan dini kanker payudara. Remaja usia antara 12-24 tahun adalah remaja generasi internet, remaja generasi ini suka dan sering berkomunikasi dengan jejaring sosial diantaranya facebook, twitter, line, whatsapp, instagram, telegram, dan lain-lain (BKKBN NTB, 2019).

Hasil penelitian ini sesuai penelitian yang dilakukan Ayulia Fardila Sari (2019) dengan hasil terdapat perbedaan pengetahuan, sikap, dan persepsi kegunaan teknologi tentang SADARI pada mahasiswa non kesehatan di Universitas Andalas sebelum dan sesudah dilakukan promosi kesehatan menggunakan media sosial instagram. Media sosial instagram dapat dimanfaatkan sebagai media promosi kesehatan untuk meningkatkan pengetahuan dan sikap masyarakat agar mengetahui informasi kesehatan khususnya deteksi dini kanker payudara melalui pemeriksaan payudara sendiri (SADARI), dikarenakan pengetahuan atau kognitif merupakan domain yang sangat penting untuk terbentuknya tindakan seseorang (Notoadmodjo, 2015).

\section{Efektivitas Media Sosial Instagram dalam Meningkatkan Pengetahuan SADARI pada Remaja}

Berdasarkan hasil uji wilcoxon didapatkan nilai $\mathrm{p}$ value $0,0001<0,05$ pada taraf signifikan 5\% bahwa terdapat perbedaan rata-rata skor pengetahuan remaja sebelum (pretest) dan sesudah 
(posttest) diberikan intervensi. Prosentase kenaikan skor pretest dan posttest didapatkan dari selisih antara nilai rata-rata pretest dan posttest yaitu sebesar 55,92\%, dan juga pada hasil feed back (AISAS) responden rata-rata menjawab setuju dengan pertanyaan tentang AISAS, sehingga dapat diartikan bahwa media sosial instagram efektif terhadap peningkatan pengetahuan tentang SADARI sebagai pencegahan dini kanker payudara pada remaja di Kabupaten Kudus.

Peningkatan pengetahauan SADARI sebagai pencegahan dini kanker payudara disebabkan karena antusias remaja tentang kesehatan reproduksi terutama kesehatan payudara yang begitu dikhawatirkan dan juga responden tertarik dengan postingan yang ada di feed tentang gambar penyakitnya sehingga mereka merasa takut dan ingin memahami lebih dalam tentang SADARI sebagai pencegahan dini kanker payudara yang ada di feed instagram @informasikesehatanmasyarakat.

Penggunaan media sosial instagram dalam meningkatkan pengetahuan efektif karena bisa dibaca dimana saja dan kapanpun mereka berada. Selain itu penyajian informasi kesehatan melalui instagram yang didominasi oleh gambar atau foto juga memudahkan responden dalam menerima informasi kesehatan. Penelitian ini sesuai dengan penelitian yang dilakukan oleh Indah Risnawati (2015) dengan kesimpulan ada hubungan antara tingkat pengetahuan tentang SADARI dengan praktik SADARI pada remaja putri. Penelitian lain yang dilakukan Rita Permatasari (2017) promosi kesehatan tentang dagusibu (Cara Tepat Penggunaan Obat) melalui media sosial instagram yang hasilnya terjadi peningkatan pengetahuan setelah diberikan intervensi media sosial instagram. Hasil penelitian ini juga sejalan dengan penelitian Emy, Nizwardi (2018) yang mengungkapkan bahwa peran media sosial berkontibusi positif terhadap upaya promosi kesehatan, pemanfaatan media sosial efektif dalam melakukan upaya promosi kesehatan dengan tujuan meningkatkan pemahaman dan memberi dukungan kepada masyarakat untuk berperilaku sehat.

\section{KESIMPULAN}

Berdasarkan hasil penelitian yang dilakukan mengenai efektivitas media sosial instagram dalam meningkatkan pengetahuan SADARI diperoleh simpulan bahwa terdapat perbedaan yang signifikan antara skor pretest dan posttest pengetahuan SADARI remaja dengan nilai sig. 0,0001 < 0,05 yang berarti bahwa media sosial instagram efektif dalam meningkatkan pengetahuan SADARI sebagai pencegahan dini kanker payudara pada remaja di Kabupaten Kudus dengan prosentase kenaikan skor $55,92 \%$ dan adanya feed back pada AISAS.

\section{UCAPAN TERIMAKASIH}

Peneliti mengucapkan terimakasih kepada ketua STIKES Cendekia Utama Kudus, Dinas Kesehatan Kudus, dan responden yang telah membantu dalam proses penelitian ini.

\section{DAFTAR PUSTAKA}

BKKBN NTB. (2019). Mengenal Remaja Generasi Z. diakses tanggal Desember 2020. [http://ntb.bkkbn.go.id/?p=1467]

Databoks. (2018). Kasus Kanker Payudara Paling Banyak Terjadi di Indonesia, diakses tanggal 03 Januari 2020, [https://databoks.katadata.co.id/da tapublish/2019/06/03/kasuskanker- payudara-paling-banyakterjadi-di-indonesia]

Databoks. (2019). Penggunaan Instagram di Indonesia, diakses tanggal 25 Januari2019.

[https://databoks.katadata.co.id/da tapublish/2018/02/09/berapa pengguna-instagram-dariindonesia] 
Dewanti, P. (2019). Efektivitas Model AISAS dalam Komunikasi Pemasaran pada Fitur Promosi Instagram (Doctoral dissertation, STIE YKPN)

Dinas Kesehatan Kabupaten Kudus (2020). Data Kasus Kanker Payudara 2018, Dinas Kesehatan Kabupaten, Kudus

Dinas Kesehatan Kabupaten Kudus (2020). Data Kasus Kanker Payudara 2019, Dinas Kesehatan Kabupaten : Kudus

Sari, Ayulia Fardila. (2019). Promosi Kesehatan SADARI Menggunakan Instagram pada Mahasiswi Non Kesehatan Universitas Andalas. Jurnal MKMI, 5 (3), 253-263

Handayani, S., \& Sudarmiati, S. (2012). Pengetahuan remaja putri tentang cara melakukan SADARI. Jurnal Keperawatan Diponegoro, 1(1), 93-100

Leonita, E., \& Jalinus, N. (2018). Peran Media Sosial dalam Upaya Promosi Kesehatan: Tinjauan Literatur. INVOTEK: Jurnal Inovasi Vokasional dan Teknologi, 18(2), 25-34

Machfoedz, Ircham \& Eko Suryani. (2013). Pendidikan Kesehatan bagian dari Promosi Kesehatan. Yogyakarta: Fitramaya

Notoatmodjo, Soekidjo. (2014). Promosi Kesehatan dan Perilaku Kesehatan. Jakarta: Rineka Cipta

Profil Kesehatan Provinsi Jawa Tengah. (2018). Profil Jateng 2017, Dinas Kesehatan Provinsi Jawa Tengah, Semarang

Profil Kesehatan Provinsi Jawa Tengah. (2019). Profil Jateng 2018, Dinas Kesehatan Provinsi Jawa Tengah, Semarang

Permatasari, Rita. (2017) Efektivitas Penggunaan Media Sosial Berupa Facebook dan Instagram Untuk Meningkatkan Pengetahuan Mahasiswa Non Kesehatan
Tentang Dagusibu di Universitas Muhammadiyah Purwokerto [Skripsi]. Purwokerto: Universitas Muhammadiyah Purwokerto.

Rahmawati, J. K. (2019). Efektivitas Aisas Melalui Media Sosial Instagram dalam Meningkatkan Brand Awareness BLP Beauty sebagai Kosmetik Local Brand $=$ The effectiveness of aisas through instagram social media in increasing blp beauty awareness brand as cosmetic local brand (Doctoral dissertation, Universitas Pelita Harapan)

Risnawati Indah. (2015). Hubungan Tingkat Pengetahuan Tentang Pemeriksaan Payudara Sendiri (SADARI) dengan Praktik Pemeriksaan Payudara Sendiri (SADARI) pada Remaja, JIKK, Vol.6 (2), 2 Juli 2015, 65-71

Savitri,Astrid, dkk. (2015). Kupas Tuntas KANKER Payudara Leher Rahim \& Rahim. Yogyakarta : Pustaka Baru Press

Suastina, I. D. A. R., Ticoalu, H., \& Onibala, F. (2013). Pengaruh Pendidikan Kesehatan terhadap Tingkat Pengetahuan Siswi tentang SADARI sebagai Deteksi Dini Kanker Payudara di SMA Negeri 1 Manado. Jurnal Keperawatan, $1(1)$

Sugiyono. (2017). Metode Penelitian Kuantitatif, Kualitatif, dan R\&D. Bandung: Alfabeta 